\title{
HUBUNGAN ANTARA KEIKUTSERTAAN SENAM HAMIL DENGAN KETEPATAN WAKTU PROSES PERSALINAN KALA II DI KLINIK AS SYIFA SURADADI KABUPATEN TEGAL
}

\author{
Rusmini, ${ }^{1}$ Ulfatul Latifah, ${ }^{2}$ Tri Ayu Agustina ${ }^{3}$ \\ Email: ulfatul.bidan@poltektegal.ac.id \\ 1,2,3 Program Studi D III Kebidanan Politeknik Harapan Bersama \\ Jl.Mataram no.09 Pesurungan Lor Kota Tegal
}

\begin{abstract}
Abstrak
Angka kematian maternal dan perinatal di Indonesia masih cukup tinggi, salah satu sebab tinggi nya kematian adalah akibat persalinan yang lama. Senam hamil merupakan suatu program latihan untuk mempersiapkan kondisi fisik ibu dengan menjaga kondisi otot-otot dan persendian yang berperan dalam proses persalinan, serta metode penting untuk mempertahankan atau memperbaiki keseimbngan fisik ibu hamil dan merupakan terapi latihan yang diberikan pada ibu hamil dengan tujuan mencapai persalian yang cepat, mudah dan aman serta mencegah terjadinya kala II. Tujuan penelitian ini adalah diketahuinya hubungan antara keikutsertaan senam hamil dengan ketepatan waktu proses persalinan Kala II Di Klinik Asyifa Suradadi KabupatenTegalTahun 2016. Desain penelitian ini adalah metode eksperimen dengan pengambilan data primer dan sekunder. Populasi dalam penelitian ini sebanyak 30 dan pengambilan sampel dilakukan dengan teknik "Quota sampling" menetapkan sejumlah anggota sempel secara quantum atau jatah. Diperoleh jumlah sampel sebanyak 30 orang. Analisis data dengan Chi Square. Dari 30 responden yang mengikuti senam hamil secara teratur di Klinik Asyfa Suradadi Kabupaten Tegal sebanyak 15 orang $(50 \%)$ dan yang tidak mengikuti senam hamil 15 orang $(50 \%)$. Waktu kala II persalinan yang tepat sebanyak $20(66.7 \%)$, dan yang tidak tepat sebanyak $10(33.3 \%)$. Hasil uji statistik dengan "Uji Chi Square" di dapatkan nilai p-value $0,000<0,05$ sehingga dapat disimpulkan terdapat hubungan yang signifikan antara keikut sertaan senam hamil dengan ketepatan waktu proses persalinan kala II pada Di Klinik Asyifa Suradadi Kabupaten Tegal Tahun 2016. Saran bagi instasi kesehatan diharapkan dapat meningkatkan sosialisasi tentang senam hamil dan menerapkan pada pelayanan ANC dan dalam kelas hamil.
\end{abstract}

Kata Kunci :Ibu Hamil, Senam, Waktu Persalinan Kala II

\section{Pendahuluan}

Angka kematian maternal dan perinatal merupakan indikator keberhasilan pelayanan kesehatan, khususnya pelayanan kebidanan dan perinatal. Sampai sekarang angka kematian maternal dan perinatal di Indonesia masih cukup tinggi. Salah satu sebab tingginya kematian maternal dan perinatal di Indonesia dan negara-negara sedang berkembang lainnya salah satunya adalah akibat persalinan lama. Target Angka Kematian Ibu (AKI) di Indonesia pada tahun 2015 adalah 102 kematian per 100.000 kelahiran hidup. Sementara itu berdasarkan Survei Demografi Dan Kesehatan Indonesia (SDKI) Tahun 2012, AKI yang berkaitan dengan kehamilan, persalinan, dan nifas sebesar 359 per 100.000 kelahiran hidup, dan pada tahun 2014 tercatat 357 kasus. Angka ini masih cukup jauh dari target yang harus dicapai pada tahun $2015^{1}$.

Profil Kesehatan Jawa Tengah (2014) AKI sebanyak 711 kasus atau 126,55/ $100.000 \mathrm{KH}$. Angka ini mengalami peningkatan dari jumlah AKI tahun 2013 yaitu sebanyak 668 kasus atau sebanyak 118,62/ 100.000 KH. Sebesar 57,95\% kematian maternal terjadi pada waktu nifas, pada waktu hamil sebesar $27,00 \%$ dan pada waktu persalinan sebesar 15,05\%. Sementara berdasarkan kelompok umur, kejadian kematian maternal terbanyak adalah pada usia produktif (20-34 tahun) sebesar $62,02 \%$, kemudian pada kelompok umur $\geq 35$ tahun sebesar $30,52 \%$ dan pada kelompok umur $\leq 20$ tahun sebesar 7,45\% ${ }^{2}$.

Sedangkan AKI ditahun 2015 sampai bulan November di Kabupaten Tegal itu sendiri sebanyak 29 per 100.000 kelahiran hidup. Hal ini menunjukkan adanya 
penurunan AKI di Kabupaten Tegal tahun 2015 melihat dari jumalah AKI tahun 2014 yaitu sebanyak 47 per 100.000 kelahiran hidup ${ }^{3}$.

Persalinan merupakan proses pengeluaran hasil konsepsi (janin dan plasenta) yang telah cukup bulan atau dapat hidup diluar kandungan melalui jalan lahir atau dengan bantuan atau tanpa bantuan( kekuatan sendiri) ${ }^{4}$.

Lamanya persalinan mempunyai resiko menyebabkan kematian perinatal dua kali dibandingkan dengan persalinan normal. Lamanya proses persalinan dipengaruhi oleh 5 faktor penyebab persalian yaitu: tenaga(power), janin(pessenger), jalan lahir(pessage), psikis ibu bersalian, dan penolong 5 .

Lamanya persalinan yang terjadi pada kala II merupakan fase terakhir dari suatu persalinan yang berlangsung terlalu lama sehingga timbul gejala gejala seperti dehidrasi, infeksi, kelelahan ibu serta asfiksia dan kematian janin dalam kandungan / Intra Uterin Fetal Death ${ }^{6}$.

Sampai saat ini yang dapat di kendalikan adalah masalah tenaga atau power yaitu dengan senam hamil dan energi yang cukup menjelang persalinan. Senam hamil merupakan suatu program latihan bagi ibu sehat untuk mempersiapkan kondisi fisik ibu dengan menjaga kondisi otot-otot dan persendian yang berperan dalam proses persalinan. ${ }^{7}$ serta metode penting untuk mempertahankan atau memperbaiki keseimbngan fisik ibu hamil dan merupakan terapi latihan yang diberikan pada ibu hamil dengan tujuan mencapai persalian yang cepat, mudah dan $\operatorname{aman}^{8}$. Serta terapi latihan gerak untuk mempersiapkan ibu hamil, secara fisik atau mental pada persalinan cepat, aman dan spontan'.

Kelainan pada faktor tenaga bisa disebabkan karena terjadinya inersia (his yang tidak sesuai dengan fasenya), inkoordinit (his tidak teratur, tidak ada koordinasi dan sinkronisasi antara kontraksi bagian-bagiannya) dan tetanik (his yang terlampau kuat dan terlalu sering sehingga tidak ada relaksasi rahim). Hal tersebut di atas dapat menyebabkan kemacetan persalinan, jika tidak segera ditangani maka akan mengakibatkan gawat janin dan rahim ibu pecah. Upaya yang bisa dilakukan ibu hamil agar persalinan berjalan lancar dapat dikendalikan dengan melakukan senam hamil ${ }^{10}$.

Berdasarkan study pendahuluan pada tanggal 2 Mei 2016 Di Klinik As Syifa Suradadi Kabupaten Tegal dengan wawancara lansung pada salah satu ibu bersalin yang mengikuti senam hamil adalah proses persalinan yang terjadi sesuai dengan hari perkiraan lahir (HPL) dan ibu mengatakan mengikuti senam hamil seminggu sekali dan mempratekannya selama dirumah, ibu merasa lebih tenang dan bisa menahan rasa sakitnya dengan cara tarik nafas panjang, dan pada saat pembukaannya sudah lengkap ibu bisa mengejan dengan baik dan benar. Waktu persalinan yang berlangsung juga tidak terlalu lama pada kala 2 berlangsung sekitar $1 / 2 \mathrm{jam}$.

Berdasarkan latar belakang diatas penulis tertarik untuk melakukan penelitian dengan judul " Hubungan antara senam hamil dengan ketepatan waktu proses persalinan pada primigravida di Klinik As Syifa Suradadi Kabupaten Tegal Tahun 2016"

Penelitian ini bertujuan untuk mengetahui hubungan antara keikutsertaan senam hamil dengan ketepatan proses persalinan kala II di Klinik As Syifa Suradadi Kabupaten Tegal.

\section{Metode penelitian}

Jenis penelitian ini adalah analitik dengan rencangan penelitian menggunakan pendekatan metode penelitian eksperimen adalah suatu penelitian dengan menggunakan kegiatan percobaan yang bertujuan untuk mengetahui gejala atau pengaruh yang timbul, sebagai akibat dari adanya perlakuan tertentu atau eksperimen tersebut. ${ }^{11}$

Populasi dari penelitian ini adalah ibu bersalin primigravida pada bulan Mei Juni 2016, Di Klinik As Syifa Suradadi Kabupaten Tegal.

Jumlah sampel dalam penelitian ini sebanyak 30, pengambilan sampel dengan menggunakan Quota sampling yaitu dilakukan dengan cara menetapkan 
sejumlah anggota sempel secara quotum atau jatah

Kriteria sempel pada penelitian ini adalah ibu bersalin yang mengikuti senam hamil secara rutin, tidak menikuti senam hamil Di Klinik As Syifa Suradadi Kabupaten Tegal.

Penelitian ini dilakukan dengan cara observai langsung, kemudihan data dilakukan analisa menggunakan analisa univariat dan bivariat. Analisis data yang digunakan dengan menggunakan Chi Square.

\section{Hasil dan Pembahasan}

Penelitian ini dilakukan pada 30 responden yaitu 15 ibu bersalin yang menikuti senam hamil dan 15 ibubersalin yang tidak mengikuti senam hamil.

A. Analisa Univariat

Tabel 1. Distribusi frekuensi ibu bersalin yang mengikuti senam hamil Di Klinik Asyfa Suradadi Kab. Tegal 2016

\begin{tabular}{llll}
\hline No & Senam Hamil & Jumlah & \% \\
& & & \\
\hline 1 & Rutin & 15 & 50,0 \\
2 & Tidak ikut senam & 15 & 50,0 \\
\hline & Total & 30 & 100,0 \\
\hline
\end{tabular}

Sumber : Data Sekunder

Berdasarkan penelitian menunjukan bahwa responden yang mengikuti senam hamil secara teratur di Klinik Asyfa Suradadi Kabupaten Tegal sebanyak 15 orang $(50 \%)$ dan yang tidak mengikuti senam hamil 15 orang $(50 \%)$.

Senam hamil bertujuan untuk memperkuat menguatkan dan mempertahankan elastisitas otot- otot dinding perut, otot- otot dasar panggul, ligamen, jaringan yang berperan dalam mekanisme persalinan ${ }^{10}$.

Keteraturan senam hamil di Klinik Asyifa Suradadi Kabupaten Tegal lebih dikarenakan pelaksanaan senam hamil yang sudah terjadwal yaitu $1 \mathrm{x}$ dalam seminggu di Klinik Asyif a Suradadi Kabupaten Tegal. Dan sebagaian besar alasan ibu tidak mengikuti senam hamil dikarenakan rumahnya terlalu jauh, tidak ada yang mengantar dan sebagian ada yang jualan.
Senam hamil dilakukan pada usia kehamilan 28 minggu dan Senam hamil terbukti memiliki dampak positif dalam menyeimbangkan kondisi psikologis ibu hamil. Tiga komponen inti senam hamil yaitu latihan pernafasan, latihan penguatan dan peregangan otot, serta latihan relaksasi dapat mengandung efek relaksasi yang dapat mempengaruhi psikologi ibu saat menjalani persalinan.

Ibu hamil yang melakukan senam hamil lebih sering atau teratur, proses persalinan relative berlangsung secara spontan dan waktu persalinan berlangsung dengan tepat. Peningkatan stamina yang dibutuhkan saat proses persalinan otot-otot akan terbentuk dan kuat dibandingkan dengan ibu yang jarang ataupun tidak pernah mengikuti senam hamil. Ibu bersalin yang tidak mengikuti senam hamil secara sering atau teratur sebagian besar mengalami proses persalinan tidak normal karena ibu jarang ataupun tidak pernah mengikuti latihan-latihan fisik atau olah raga selama hamil sehingga otot-otot dinding perut dan otot-otot dasar panggul menjadi kaku dan tidak dapat berfungsi dengan sempurna dalam proses persalinan ${ }^{10}$.

Tabel 2. Distribusi frekuensi ketepatan waktu proses persalinan kala II Di Klinik Asyfa Suradadi Kab. Tegal 2016.

\begin{tabular}{|c|c|c|c|}
\hline No & $\begin{array}{l}\text { Waktu persalinan } \\
\text { kala II }\end{array}$ & $\mathbf{F}$ & $\%$ \\
\hline 1. & Tepat & 20 & 66.7 \\
\hline 2. & Tidak tepat & 10 & 33.3 \\
\hline & Total & 30 & 100.0 \\
\hline
\end{tabular}

Sumber : Data Primer

Dari hasil observasi persalinan yang dilakukan pada bulan Mei- Juni 2016 di Klinik Asyifa Suradadi Kabupaten Tegal dari 30 responden ibu bersalin, waktu kala II persalinan yang tepat sebanyak $20(66.7 \%)$, dan yang tidak tepat sebanyak $10(33.3 \%)$.

Dari hasil penelitian bahwa ibu bersalin yang mengikuti senam hamil secara rutinwaktu proses persalinan kala II terjadi dengan tepat sebanyak 15 responden (100\%), dan yang tidak mengikuti senam hamil tetapi waktu proses persalinan kala II nya terjadi dengan tepat yaitu 5 responden 
(33,3\%), dan yang tidak tepat yaitu 10 responden $(16,7 \%)$.

Proses persalinan dipengaruhi oleh 5 faktor penting yaitu: faktor power, passage, passenger, psikis ibu dan penolong. Power disini adalah kontraksi uterus dan kekuatan ibu untuk mengejan. Faktor lain yang berpengaruh terhadap persalinan adalah faktor Passanger (janin), yang meliputi sikap janin dalam rahim, letak janin, presentasi janin, bagian terbawah janin dan posisi janin. Kelainan pada salah satu kondisi janin tersebut dapat berakibat sulitnya kelahiran bayi yang mana harus dilakukan suatu tindakan seperti vacuum maupun caesar ${ }^{12}$.

Faktor psikis ibu tidak kalah pentingnya untuk kelancaran proses persalinan, bila ibu yang sedang bersalin merasa cemas dan takut menghadapi persalinan, mereka akan mengeluarkan adrenalin yang menghambat pelepasan oksitosin yang diperlukan untuk kemajuan persalinan hingga nifas dan ibu yang dalam kondisi stres otot-otot tubuhnya termasuk otot rahim mengalami spasme yang dapat meningkatkan rasa nyeri persalinan sehingga menghambat proses persalinan. Faktor penolong persalinan memegang peranan yang sangat peting oleh karena keberhasilan persalinan menghasilkan ibu dan bayi yang sehat dan selamat di tentukan oleh penolong yang trampil dan kompeten. Apabila salah satu dari lima faktor tersebut mengalami kelainan, misalnya keadaan yang menyebabkan kekuatan his tidak adekuat, kelainan pada bayi atau kelainan jalan lahir maka persalinan tidak dapat berjalan secara normal ${ }^{4}$.

Rentang waktu pada ibu bersalinan pada primigravida bisa terjadi dengan tepat yaitu sesuai dengan perkiraan hari lahir (HPL) dan biasanya waktu yang terjadi pada kala 1 sekitar 20jam dan pada kala 2 sekitar 1/2-2jam dan kala 3 berlangsung 5-30 menit. Dan waktu persalinan yang lama jika pada waktu fase laten lebih dari 8 jam dan tidak ada tanda-tanda kemajuan persalinan ${ }^{7}$.

B. Analisa Bivariat

Berdasarkan analisa bivariat menujukan bahwa berdasarkan ketepatan waktu persalinan kala II ibu yang melakukan senam hamil rutin terdapat waktu persalinan dengan tepat(100\%), sedangkan ibu yang tidak ikut senam hamil 33,3\% (5 responden) waktu persalian dengan tepat, dan $66,7 \%$ (10 responden) waktu persalinan tidak tepat.

Berdasarkan hasil analisa dengan uji korerasi Chi Square diperoleh nilai $\mathrm{x}^{2}$ hitung 15.000 dan $p$ value 0,000 berdasarkan level signifikan 0.05 dengan $\mathrm{df}=1$ maka nilai $\mathrm{x}^{2}$ tabel adalah 3,841 hal ini menunjukan bahwa $\mathrm{x}^{2}$ hitung lebih besar dari $\mathrm{x}^{2}$ tabel(15.000 .> 3,841) dan $p$ value lebih kecil dari $0,05(0.000<0.05)$ yang berarti Ho ditolak dan $\mathrm{Ha}$ diterima artinya ada hubungan antara senam hamil dengan ketepatan waktu proses persalinan kala II pada primigravida di Klinik As Syifa Suradadi Kabupaten Tegal.

Senam hamil yang dilakukan di Klinik Asyifa Suradadi merupakan salah satu bentuk olahraga yang berguna untuk membantu wanita hamil memperoleh power yang baik sehingga dapat memperlancar proses persalinan. Dengan latihan secara teratur kontraksi uterus menjadi lebih baik dan dapat memberikan kekuatan terhadap otot- otot dasar panggul, otot-otot dinding perut sehingga persalinan menjadi lebih singkat dan proses persalinan dapat berjalan secara spontan ${ }^{13}$.

Ibu hamil yang melakukan senam hamil lebih sering atau teratur, proses persalinan relative berlangsung secara spontan. Peningkatan stamina yang dibutuhkan saat proses persalinan otot-otot akan terbentuk dan kuat dibandingkan dengan ibu yang jarang ataupun tidak pernah mengikuti senam hamil. Ibu bersalin yang tidak mengikuti senam hamil secara sering atau teratur sebagian besar mengalami proses persalinan tidak normal karena ibu jarang ataupun tidak pernah mengikuti latihan-latihan fisik atau olah raga selama hamil sehingga otot-otot dinding perut dan otot-otot dasar panggul menjadi kaku dan tidak dapat berfungsi dengan sempurna dalam proses persalinan ${ }^{8}$. Senam hamil juga dapat berpengaruh secara bermakna terhadap proses persalinan yang normal dan spontan dibandingkan dengan yang tidak mengikuti senam hamil.

Hal ini sesuai dengan penelitian sebelumnya Sofewan (2009), dengan judul "Hubungan senam Hamil dengan Proses 
Persalinan kala II pada Primigravida di PKU Muhamadiyah Di Yogyakarta" terhadap 100 wanita primigravida dengan hasil penelitiannya adalah kejadian persalinan lama lebih minimal secara bermakna terhadap ibu yang mengikuti senam hamil, dan persalinan kala II berlangsung lebih cepat dari pada ibu yang tidak melakukan senam hamil sehingga proses persalinannya dapat berjalan dengan lancar dan meningkatkan cara persalinan spontan. ${ }^{14}$

Penelitian ini juga didukung oleh penelitian yang dilakukan oleh Nur aeni rahmawati dkk (2016) dengan judul Hubungan senam hamil terhadap lamanya proses persalinan pada ibu bersalin di wilayah kerja puskesmas bayat klaten. Mengatakan ada hubungan senam hamil terhadap lamanya proses persalinan pada ibu bersalin di wilayah kerja Puskesmas Bayat Klaten dengan nilai $\mathrm{p}$ value sebesar $0,012(\mathrm{p}<0,05){ }^{15}$

Penelitian lain yang dilakukan oleh Nurotul eniyah macmudah (2003), dengan judul Hubungan senam hamil dengan lama persalinan kala 11 pada ibu bersalin di rumah bersalin Ngudi Waras Semarang juga mengatakan ada hubungan yang bermakna antara senam hamil dengan lama persalinan kala 11 pada ibu bersalin di RB Ngudi Waras Semarang dengan nilai $p$ value 0,033 $(\mathrm{p}<0,05) \cdot{ }^{16}$

Dengan adanya pengaruh antara keikutsertaan senam hamil terhadap waktu proses selama persalinan maka diharapkan setiap ibu hamil dapat mempersiapkan kondisi fisik maupun mental untuk menghadapi proses persalinan nantinya, salah satunya adalah dengan melakukan senam hamil secara rutin.

\section{Kesimpulan}

Penelitian yang dilakukan pada 15 $(50,0 \%)$ responden yang mengikuti senam hamil rutin dan $15(50,0 \%)$ responden yang tidak mengikuti senam hamil. Dari 30 responden ibu bersalin kala II persalinan yang tepat sebanyak 20 responden $(66,7 \%)$, dan yang tidak tepat sebanyak 10 responden $(33,3 \%)$. Ada hubungan yang bermakna antara keikutsertaan senam hamil dengan ketepatan waktu proses persalinan kala II di
Klinik As Syifa Suradadi Kabupaten Tegal dengan nilai $p 0,000<\alpha 0,05$.

\section{Daftar Pustaka}

[1] Kemenkes, RI. 2015. Angka Kematian Ibu

[2] Dinkes, Jateng. 2014. Angka Kematian Ibu

[3] Dinkes, Kab Tegal. 2015. Angka Kematian Ibu

[4] Sulistyawati, A. 2010. Asuhan Kebidanan Persalinan. Jakarta : Salemba Medika

[5] Rukiyah, Yeyeh. A. 2014. Asuhan Kebidanan 2 (persalinan). Jakarta : CV Trans Info Medika

[6] Saifudin. 2006. Pelayanan Kesehatan Maternal dan Neonatal. Jakarta : Yayasan Bina Kebidanan

[7] Brayshaw, A. 2011. Senam Hamil dan Nifas. Jakarta : Buku Kedokteran EGC

[8] Maryuni, A. 2011. Senam Hamil Senam Nifas dan Terapi Musik. Jakarta : CV Trans Info Medika

[9] Widianti, Tri. A. 2010. Senam Kesehatan. Yogyakarta : Nuhu Medika

[10] Achamd. 2008. Asuhan Kebidanan Ibu Hamil. Jakarta : EGC

[11] Notoatmodjo. 2012. Metodologi Penelitian Kesehatan. Jakart : Rineka Cipta

[12] Yanti. 2009. Buku Ajar Asuhan Kebidanan. Ed4. Jakarta : EGC

[13] Mochtar, M. 2012. Sinopsis Obstetri. Jakarta : Buku Kedokteran EGC

[14] Sofewan. 2009. Hubungan Senam Hamil Dengan Proses Persalian Kala II Pada Primigravida Di PKU Muhamadiyah Di Yogyakarta.

[15] Nur aini $R$ dkk 2014. Hubungan senam hamil terhadap lamanya proses persalinan pada ibu bersalin di wilayah kerja Puskesmas Bayat Klaten. Stikes Muhamadiyah Klaten. Journal Involusi Kebidanan.Vol 6 No.11 tahun 20116.

[16] Nurotul eniyah macmudah.2013. Hubungan senam hamil dengan lama persalinan kala 11 pada ibu bersalin di rumah bersalin Ngudi Waras Semarang. 